\title{
Paper Chromatography as an Aid to the Identification of Nocardia Species
}

\author{
By I. G. MURRAY AND A. G. J. PROCTOR \\ Mycological Reference Laboratory, London School of Hygiene \\ and Tropical Medicine
}

\begin{abstract}
SUMMARY
A simple method of detecting arabinose by paper chromatography in the cell-walls of aerobic actinomycetes is described. Mycobacteria and Nocardia species are rich in arabinose while saprophytic species of Streptomyces are deficient. Pathogenic Streptomyces species tend to fall between the two extremes but Streptomyces somaliensis is apparently nearly devoid of arabinose.
\end{abstract}

\section{INTRODUCTION}

A vast number of aerobic actinomycetes have been assigned to the genera Nocardia and Streptomyces. The majority of the latter are saprophytic organisms but three members, viz. Streptomyces somaliensis, S. pelletieri and S. madurae are frequent causes of mycetoma in some parts of the world. Whether they genuinely belong to the genus Streptomyces rather than to the genus Nocardia has been disputed. In human pathology two species, Nocardia asteroides and $N$. brasiliensis, have been completely accepted as important causes of mycetoma and other diseases. Unfortunately they can on occasion be difficult to distinguish from other actinomycetes. One criterion is acid-fastness, some measure of which Nocardia species frequently but not invariably possess. When suspected isolates are not acid-fast, identification can be very difficult and if it can be shown that the detection of arabinose serves as an acceptable substitute the problem would be considerably eased.

Cummins \& Harris (1956) demonstrated that the cell-walls of Nocardia and Mycobacterium in contrast with those of Actinomyces and Streptomyces contained large amounts of arabinose. They later extended this study (Cummins \& Harris, 1958) to Actinomyces israelii (11 strains), A. bovis (10 strains), Nocardia (5 strains), Mycobacteria ( 5 strains) and a few fungi. The cell-walls of strains of both Nocardia and Mycobacterium were found to be rich in arabinose, whereas none of the other organisms, with the exception of a strain of $A$. bovis (NCTC 4501) contained any. Bishop \& Blank (1958) have demonstrated that $\mathrm{D}$-arabinose is present in the cellwalls of Nocardia asteroides. Becker, Lechevalier, Gordon \& Lechevalier (1964) have drawn attention to the detection of $\mathrm{LL}$ - and meso-diaminopimelic acid in cell-wall hydrolysates as a means of distinguishing between Nocardia and Streptomyces species. They also used paper chromatography.

In general, some isolates of both Nocardia and Streptomyces can be extremely difficult to place correctly and acid-fastness in particular is a fallible criterion. The following method of arabinose detection by paper chromatography is put forward as a method simple enough to fit into routine laboratory methods. 


\section{METHODS}

Organisms were grown in nutrient broth containing $1 \%$ dextrose $(25 \mathrm{ml}$. lots of medium in $50 \mathrm{ml}$. flasks) at $30^{\circ}$ in shake cultures for a week, except in the cases of Thermopolyspora polyspora and Micromonospora vulgaris where the temperature was raised to $45^{\circ}$. Equally good results can be had from still cultures $(50 \mathrm{ml}$. medium/100 ml. flask), but these call for incubation extended to 2 or 3 weeks. The growth was centrifuged out and washed once in water; the deposit was suspended in $3 \mathrm{ml}$. of $5 \%$ sulphuric acid and autoclaved at $5 \mathrm{lb} / \mathrm{sq}$. in. for $20 \mathrm{~min}$. Since Cummins \& Harris (1958) advised disintegrating the cells in a Mickle shaker we at first made use of sonic disintegration before acid hydrolysis but it was found that this step could be omitted without impairment of the result. After autoclaving, $1 \mathrm{~g}$. barium hydroxide was dissolved in the hydrolysate followed by 2 drops of universal indicator. Excess alkali was neutralized by the cautious addition of $5 \%$ sulphuric acid, or simply by bubbling carbon dioxide through the mixture. The barium precipitate and the remnants of the organisms were removed by centrifugation and the supernatant fluid reduced by drying over phosphorus pentoxide, or by evaporation under reduced pressure, from about $2.5 \mathrm{ml}$. to $0.3-0.5 \mathrm{ml}$.

Two methods of chromatography, both described in Chromatographic Methods (Stock \& Rice, 1963) were used:

\section{(1) Circular chromatography}

$17 \mathrm{~cm}$. circular sheets of Whatman no. 2 filter paper were used. From the concentrated extracts, spots were deposited on the circumference of a circle of $2 \cdot 5 \mathrm{~cm}$. diam. at the centre of the filter paper; each sheet of paper could conveniently accommodate six spots of which one was normally a marker of $1 \%$ arabinose. Ribose can be mixed with the arabinose and/or with the hydrolysates if any confusion with the former sugar is anticipated. A hole was punched in the centre of the paper with a pointed glass rod and a wick of tightly rolled filter paper inserted. The chamber consisted of the lids of two $15 \mathrm{~cm}$. glass Petri dishes with a layer of solvent (butanol + acetic acid + water; $4+1+5$ ) in the bottom lid. No attempt was made to conserve solvent or prevent evaporation; the whole apparatus can be set up in a few minutes and the layer of solvent presumably saturates the atmosphere in the chamber very quickly. The paper was sandwiched between the two Petri dish lids, placed rim to rim, with the wick, which must be tightly rolled and a good fit in the hole, resting in the solvent. When the solvent had run for $2 \mathrm{hr}$, the paper was cautiously dried high over a Bunsen burner after removal of the wick. The drying could equally well be carried out in a suitable oven.

\section{(2) Descending chromatography}

Chromatography was carried out in a tank on strips of Whatman 3 MM paper $5 \mathrm{~cm}$. wide using the same hydrolysates and solvent as in the circular method. The solvent was allowed to run for about $18 \mathrm{hr}$ and the paper dried as above.

In both cases the dried paper was sprayed with aniline hydrogen oxalate $(0.9 \mathrm{ml}$. re-distilled aniline in $100 \mathrm{ml}$. 0.1 M-aqueous oxalic acid: Horrocks \& Manning, 1949). This reagent gives striking results with pentoses, notably a characteristic bright red for arabinose. Ribose gives an identical colour with this reagent, but 
Cummins (1962) states that ribose very rarely occurs in these hydrolysates and then only in very small quantities. Nevertheless, trial spots of both arabinose and ribose, together with hydrolysates of organisms, were run in the manner described. Ribose moved consistently further than arabinose and could clearly be distinguished from it by its $R_{F}$ (Pl. 1, figs. 1, 2). In no case was ribose detected in a hydrolysate of the organism tested.

After spraying, the paper was again dried in the same way. Arabinose appeared as a bright red crescent or spot and there was usually also a brown hexose band nearer the origin. The $\boldsymbol{R}_{F}$ of the spots can easily be measured as the red component of the universal indicator added after hydrolysis moves with the solvent front and when dry, marks it well.

\section{RESULTS}

The method was applied to Nocardia asteroides (3 strains), N. brasiliensis (3 strains), 6 other Nocardia strains, Streptomyces madurae (2 strains), S. pelletieri (2 strains), $S$. somaliensis (4 strains), 8 saprophytic Streptomyces strains, Thermopolyspora polyspora (1 strain), Micromonospora vulgaris (1 strain) and 5 saprophytic Mycobacterium strains.

As far as arabinose content is concerned these organisms fall into three clearcut groups :

(1) Those containing a great deal of arabinose-all species of Nocardia and Mycobacterium tested.

(2) Those containing less, but still an appreciable amount of, arabinose, Streptomyces madurae, $S$. pelletieri and $T$. polyspora.

(3) Those containing no, or only a very faint trace of, arabinose, Streptomyces somaliensis, Micromonospora vulgaris and the saprophytic Streptomyces.

These results in so far as they are comparable are similar to those achieved by Cummins \& Harris $(1956,1958)$ but do not entirely tally with those published by Kwapinski (1964) who detected arabinose in, inter alia, Actinomyces but failed to do so in Streptomyces madurae and $S$. pelletieri. The culture which he describes as Nocardia madurae NCTC 1070 is according to the records of the Mycological Reference Laboratory a culture of $S$. somaliensis in which absence of arabinose is agreed.

The results are also in agreement with those of Becker et al. (1964) using diaminopimelic acid as a marker. They placed Streptomyces somaliensis with the other Streptomyces species in general because of the presence of LL-diaminopimelic acid but they placed $S$. pelletieri and $S$. madurae with the Nocardia species because of the presence of meso-diaminopimelic acid.

\section{DISCUSSION}

Most species of the genus Streptomyces are clearly differentiated from species of Nocardia and Mycobacterium by the arabinose content of the cell-walls, the apparent anomalies being the three pathogens, $S$. madurae, $S$. pelletieri and $S$. somaliensis, whose true taxonomic position has been disputed. These three organisms were generally, but not constantly, regarded as members of the genus Nocardia till Gonzalez-Ochoa \& Sandoval (1955) transferred them to Streptomyces on the basis of their spore formation under certain conditions of culture. Mackinnon \& Arta- 
gaveytia-Allende (1956) considered this question unsettled and it has since been shown that Nocardia asteroides (Gordon \& Mihm, 1958) can produce spores indistinguishable from those associated with the genus Streptomyces. It is also interesting to note that Gonzalez-Ochoa \& Vazquez-Hoyos (1953) described a serological separation that agrees fairly closely with our separation on the basis of the arabinose content; their four groups were:

(1) 'Bovis' group, anaerobic Actinomyces; species, N. asteroides and N. brasiliensis.

(2) 'Somaliensis' group; only $S$. somaliensis.

(3) 'Madurae' group; $S$. madurae and $S$. pelletieri.

(4) 'Paraguayensis' group, saprophytic Streptomyces species.

Descending chromatography gives better separation of spots than circular chromatography but takes longer and calls for somewhat more sophisticated apparatus. The very simple circular method described here serves to make an adequate distinction between the presence and absence of arabinose in cell-wall hydrolysates of the organisms under consideration. Possible confusion due to the presence of ribose can be avoided by running the hydrolysates with and without a ribose marker. The ribose appears as a spot beyond the adjacent arabinose spots.

We are indebted to Dr J. Marks of the Tuberculosis Reference Laboratory, Cardiff, for supplying cultures of Mycobacterium.

\section{REFERENCES}

Becker, B., Lechevalier, M. P., Gordon, R. E. \& Lechevalier, H. A. (1964). Rapid differentiation between Nocardia and Streptomyces by paper chromatography of whole cell hydrolysates. Appl. Microbiology, 12, 421.

Bishop, C. T. \& Blank, F. (1958). The chemical composition of the Actinomycetales. Isolation of a polysaccharide containing D-arabinose and D-galactose from Nocardia asteroides. J. gen. Microbiol. 4, 35.

Cummins, C. S. (1962). Chemical composition and antigenic structure of cell walls of Corynebacterium, Mycobacterium, Nocardia, Actinomyces and Arthrobacter. J. gen. Microbiol. 28, 35.

Cummrns, C. S. \& Harris, H. (1956). A comparison of cell-wall composition in Nocardia, Actinomyces, Mycobacterium and Propionibacterium. J. gen. Microbiol. 15, ix.

Cummins, C. S. \& Harris, H. (1958). Studies of the cell-wall composition and taxonomy of Actinomycetales and related groups. J. gen. Microbiol. 18, 173.

Gonzalez-OchoA, A. \& Sandoval, M. A. (1955). Characteristicas de las Actinomicetes patogenos mas communes. Revta Inst. Salubr. Enferm. trop., Méx. 15, 149.

Gonzalez-OchoA, A. \& Vazquez-Hoyos, A. (1953). Relaciones serologicas de los principales Actinomycetes patogenos. Revta Inst. Salubr. Enferm. trop., Méx. 13, 177.

Gordon, R. E. \& Minm, J. M. (1958). Sporulation by two strains of Nocardia asteroides. J. Bact. 75, 239.

Horrocks, R. H. \& Manning, G. B. (1949). Partition chromatography on paper. Identification of reducing substances in urine. Lancet, $i, 1042$.

Kwapinski, J. B. (1964). Antigenic structure of the Actinomycetales. J. Bact. 88, 1211.

Mackinnon, J. E. \& Artagaveytia-Allende, R. C. (1956). The main species of pathogenic aerobic Actinomycetes causing Mycetomas. Trans. Soc. trop. Med. Hyg. 50, 31.

Stock, R. \& Rice, C. B. G. (1963). Chromatographic Methods. London: Chapman \& Hall. 



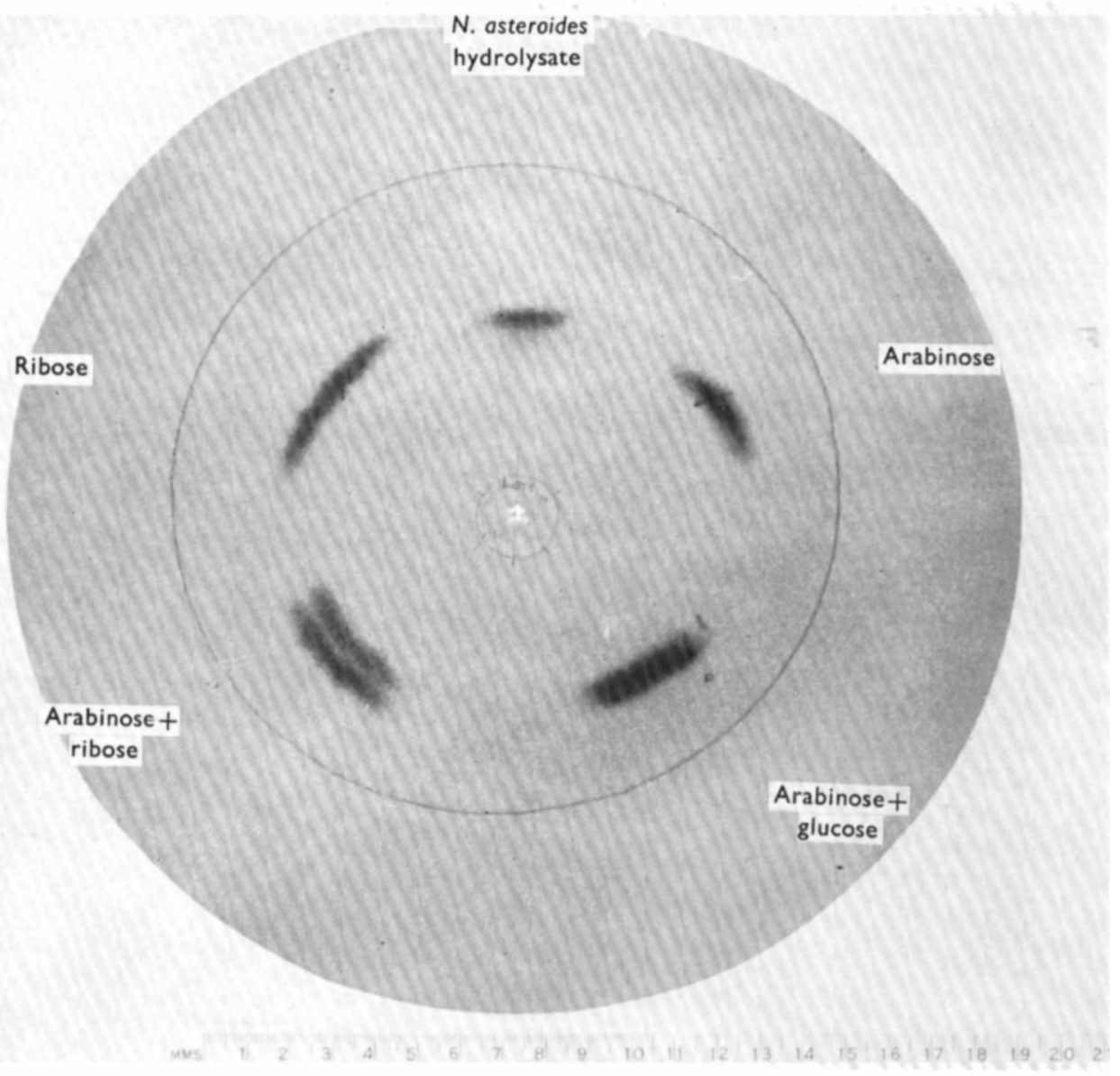

Fig. 1

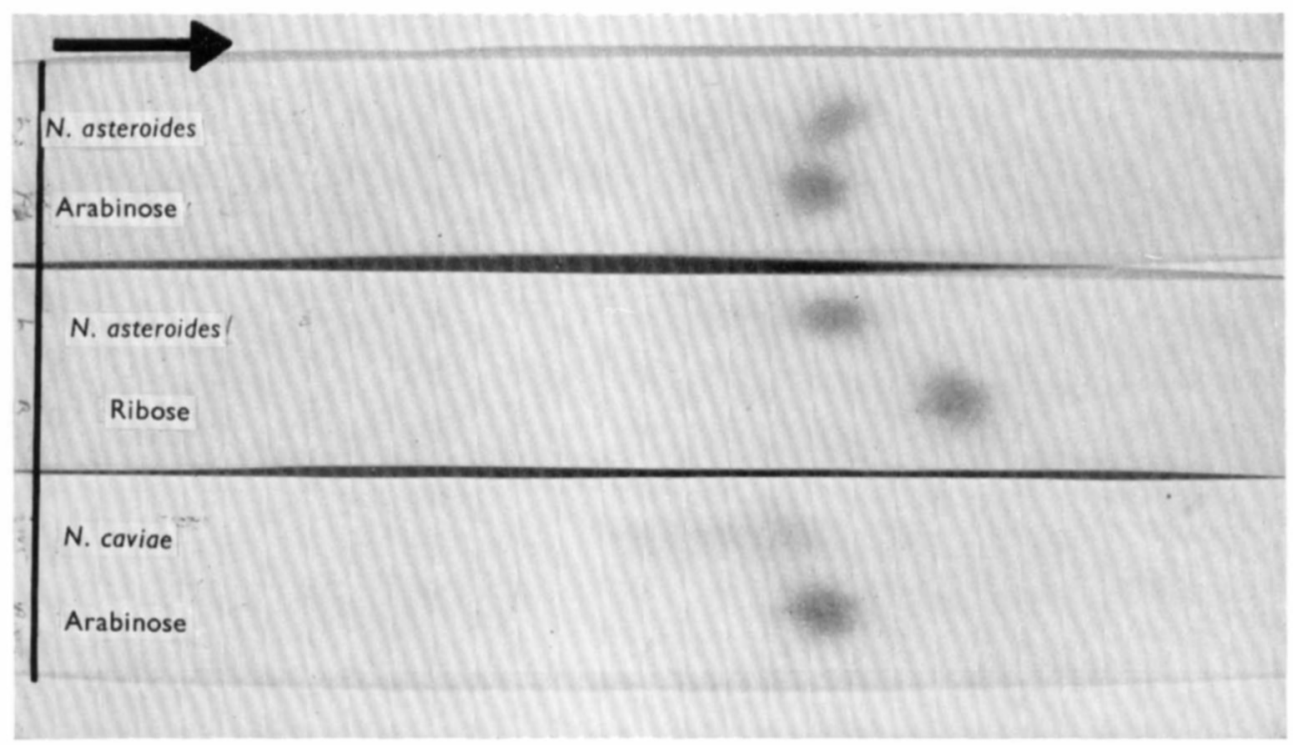

Fig. 2 


\section{EXPLANATION OF PLATE}

Fig. 1. The dark crescents mark the movement of several sugars and of a hydrolysate of N. asteroides.

Fig. 2. The dark spots mark the movements of two pentoses and two species of Nocardia (half natural size). 